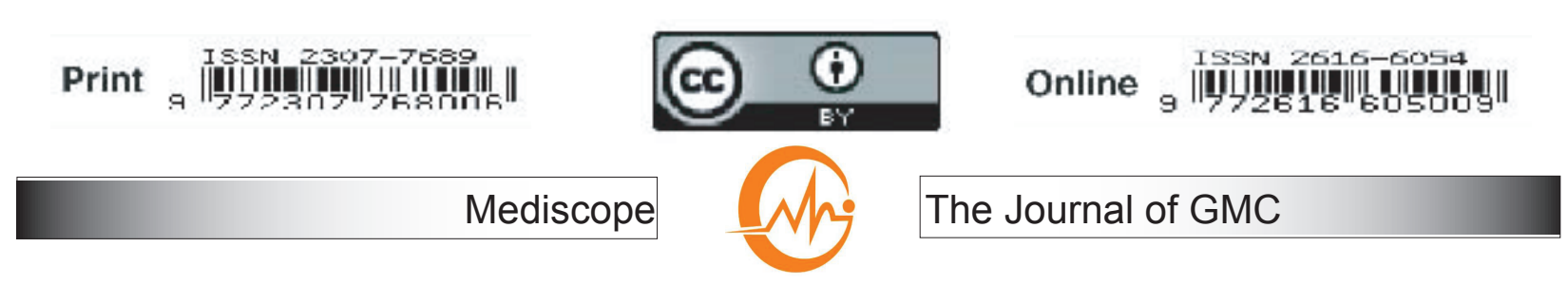

\title{
Sexual and reproductive health needs of people living with HIVIAIDS and the social responses in association with stigma and discrimination
}

\author{
SK Mallick ${ }^{1}$, T Roy ${ }^{2}$
}

\begin{abstract}
This cross-sectional study aimed at determining the sexual and reproductive health needs as well as to reveal the level and manifestation of stigma and discrimination associated with the daily lives of the people living with HIVIAIDS (PLWHA) at Khulna City Area in Bangladesh. The sample size was 20 , which was selected purposively, and data were collected by the interviewers from August 2013 to December 2013. The findings of the study revealed that extra marital sexual relationships, partners' infection and blood transmission played a dominant role as the medium of HIV infection. NGOs were the predominant source of getting health care facilities for the PLWHA and they had to wait for a month to receive STIs treatment and the counseling support, which increased their vulnerability towards AIDS. A number of respondents were eager to conceive and, in this case, treatment and counseling support before and after conception, proper nutrition support, prevention of mother to child transmission support and high cost medicine support were needed for them. The facts of stigma and discrimination, the restriction placed on their free movement, exclusion from social and religious functions, opportunities and participation on the social and economic processes had direct consequences on their daily lives. Therefore, IGA support, ensure quality treatment in the stigma free environment, and widespread awareness campaign regarding HIVIAIDS related issues were highly recommended by the PLWHA.
\end{abstract}

Key words: HIVIAIDS, Reproductive health, Stigma and discrimination, Quality social life

\section{Introduction}

In South Asia, the HIV epidemic is quite heterogeneous in its dynamics and scope. Bangladesh borders with India and Myanmar and is in close proximity with Nepal where the epidemic is severe. Bangladesh is considered to be at risk for a large-scale HIV epidemic because of the variety and gravity of risk factors which might cause the spread of HIV. ${ }^{1}$ Although still considered to be a low prevalence country, Bangladesh remains extremely vulnerable to an HIV epidemic, given its dire poverty, overpopulation, gender inequality and high levels of transactional sex. The emergence of a generalized HIV epidemic would be a disaster that povertystricken Bangladesh could ill-afford. ${ }^{2}$ it is feared that the HIV epidemic in Bangladesh may emulate the situation in India with a rapidly increasing prevalence of HIV sero

1. Subrata Kumar Mallick, Assistant Professor, Department of Sociology, Darshana Government College, Chuadanga.

2. Dr. Tuhin Roy, Associate Professor, Sociology Discipline, Khulna University, Khulna. Email: tuhinroy41@gmail.com 
positivity in high-risk groups spreading to general population. ${ }^{3}$

In Bangladesh, the first HIV case was detected in 1989, and since then the cases have been steadily increasing, as have all the potential risk factors. The HIV prevalence in the general population appeared low $(<0.2 \%)$ and was estimated as $<1 \%$ in all risk groups except for injecting drug users (IDU) 7\%1. Although the exact number of HIV cases was not known, by December 1, 2007, 1,207 cases of HIVIAIDS had been confirmed; of these people 365 had developed AIDS and 123 had died. There had been a steady rise in the annual number of reported cases of HIV over the last two years. In 2006, 216 new cases of HIV were reported while in 2007, 333 new cases of HIV were reported, including 125 new cases of AIDS and 14 deaths. These numbers were most likely an underestimate due to the voluntary nature of the sero-surveillance, the limited capacity for HIV testing and stigma associated with HIV positive status. ${ }^{4}$ This indicated both the likelihood of incomplete reporting and the potential for a rapid growth in the epidemic.

There is also little doubt that the country's limited facilities for sentinel surveillance and voluntary counseling and testing, as well as the social stigma and discrimination attached to HIV, contribute to an understatement of the real incidence of HIV. Moreover, married women who only have sex with their husbands are at growing risk of HIV and sexually transmitted infections (STIs) due to behavior of men who visit sex workers and sometimes engage in injecting practices.5 If this situation continues, Bangladesh will face a crisis that, as a developing country, it does not have the resources to tackle; it will be unable to mitigate the harmful impact of widespread HIVIAIDS, and will especially be unable to afford the medication cost. Even if only $1 \%$ of the general population becomes infected with HIV, there will be 1.5 million people infected. ${ }^{1}$ Therefore, there is a pressing need to take steps to prevent this occurring.

Since the beginning of the AIDS epidemic, stigma and discrimination have universally accompanied diagnosis of HIV.6 The stigma associated with HIV is insidious and has led to disturbing levels of AIDS-related discrimination, which affect the quality of people's lives and impact on people's ability to access care and support. ${ }^{7}$ Perceived discrimination may be greater than actual or enacted stigma. Nonetheless, the stigma associated with HIV and the subsequent fear of abuse or rejection deter many people from testing for HIV and inhibit people diagnosed with HIV from disclosing their status to others. ${ }^{8}$ This ultimately thwarts efforts to prevent further HIV transmission. The HIVIAIDS pandemic can be described as one plagued by social meaning. More than twenty years into the epidemic it is evident that we are not only dealing with the biological effects of a virus; we are also facing the negative social meanings attributed to HIVIAIDS and the people who live with it. These negative socially shared meanings ascribed to the epidemic have been described as AIDS stigma and its consequences are disastrous for people living with HIVIAIDS (PLWHA) as they entail depression, denial of health services, and ostracism, among others. ${ }^{9}$

The magnitude of the stigma surrounding HIVIAIDS is reflected in the coining of the term "AIDS-related stigma" or "AIDS stigma". 9 The myths that surround the HIVIAIDS epidemic contribute to this stigmatizing process. Among the social meanings attributed to the epidemic we find that HIV+ people are sometimes perceived as invasive agents in a "healthy" society. ${ }^{10}$

Based on above-mentioned background, the study has focused on the sexual and reproductive health needs of the PLWHA and it has also keen to identify the social responses of 
stigma and discrimination associated with them in the local context.

\section{Materials and methods}

This study is exploratory in nature, thereby cross-sectional types of descriptive study. It was a combination of quantitative and qualitative research method. Data were collected from the HIV positives of Khulna City Corporation Area. In Khulna City Corporation area total identified HIV cases were 35 (HIVIAIDS Light for Life Project-World Vision Bangladesh 2009, Geon Health Foundation, 2010). It is quite impossible to use standard random sampling for collecting data among the hidden population like HIV positives. So, non-probability sampling (snowball sampling) was used to gain in-depth information. HIV positives were selected from those who were getting support from NGOs like World Vision Bangladesh, Geon Health Foundation and in this study the sample size was 20. An inter view schedule was used to collect data from the respondents by face to face interview with the informed consent. Beside this few case studies were also incorporated to gain in-depth data. After the collection of data from the field level, total data were edited, coded and prepared for analysis.

\section{Results}

Health problems faced by the PLWHA: Beside HIV infection, the study also focused on the overall health problems faced by the respondents and with regards to health problems, multiple responses were found and it was reported that most of the respondents $(90 \%)$ were suffering from different types of health complications. Among others, fever was predominated which counted $60 \%$, followed by decreased physical strength $50 \%$, decreased appetite $45 \%$, diarrhoea $30 \%$, loss of weight $20 \%$, and skin diseases 10\% (Table 01).

Table 01: Health problems faced by the PLWHA

\begin{tabular}{|l|c|c|}
\hline Types of Health Problems & Frequency & Percentage \\
\hline Fever & 12 & 60.0 \\
\hline Decreased Physical Strength & 10 & 50.0 \\
\hline Decreased Appetite & 9 & 45.0 \\
\hline Diarrhoea & 7 & 35.0 \\
\hline Other (Vomiting) & 5 & 25.0 \\
\hline Loss of Weight & 4 & 20.0 \\
\hline Skin Disease & 2 & 10.0 \\
\hline
\end{tabular}

Note: Increased Percentage due to multiple responses.

Sources of getting health care support: The study revealed that NGOs were the predominant source of getting health care facilities for the PLWHA. The PLWHA reported that without NGO they had a little chance to receive health care support. In every month Health Project of World Vision Bangladesh-Khulna ADP arranged a day long health session for the PLWHA, and they got normal health care facilities like medical checkup, medication support and so on. They also viewed that normally they did not get any health care facilities from the government hospitals or local clinics.
Constraints in getting health care: The respondents reported that they had to face different types of constraints in getting health care support and with regards to constraints in getting health care, $80 \%$ respondents reported that economic problem was the main barrier in getting health care. High cost of health care (55\%) and lack of confidentiality (45\%) were identified another significant constraint in getting health care support (Table 02). 
Table 02: Constraints in getting health care

\begin{tabular}{|l|c|c|}
\hline \multicolumn{1}{|c|}{ Constraints } & Frequency & Percentage \\
\hline Economic Problems & 16 & 80.0 \\
\hline High Cost of Health Care & 11 & 55.0 \\
\hline Lack of Confidentiality & 9 & 45.0 \\
\hline Negative Attitude of Health Service Providers & 5 & 25.0 \\
\hline Long Waiting Times & 3 & 15.0 \\
\hline
\end{tabular}

Note: Increased Percentage due to multiple responses.

The study also revealed that the incidence of negative attitude of health service providers $(25 \%)$ and long waiting times (15\%) were experienced by the PLWHA.

\section{Sexual and reproductive health needs of the respondents:}

STIs treatment facility is very much essential for the people living with HIVIAIDS. The study reveals that most of the respondents had the opportunity to receive STIs/RTI treatment and counseling support. According to the PLWHA, NGOs were the main source for getting STIs/RTI treatment and counseling support. They mainly received support from the World Vision Bangladesh-Sundarbans ADP. The PLWHA also reported that they did not get any treatment facilities from the government hospital or other institutions. It was revealed that most of the respondents had the opportunity to receive STIS/RTI treatment and counseling from NGO. But with regards to the sufficiency of the treatment support, most of the respondents explicated that the STIs treatment and counseling support was not enough for them. On the other hand, they mainly received the normal treatment facilities and they also didn't receive quality counseling support because there had no recognized counselor.

In terms of STIs/RTI treatment facility, the respondents reported that the facilities they received were not sufficient for them and they laid emphasis on the following issues. A monthly medical camp arranged for them and they received primary health care support as well as the STIs related treatment. According to them the problem was that they had to wait a month to get the treatment opportunity as a result they didn't get the regular basis treatment in time, and they didn't have the opportunity to receive free medical test opportunity. On the other hand, the respondents viewed that they didn't get opportunity to admit at local hospitals or clinic due to lack of confidentiality and economic hardship.

NGO was the main source of health care support for the PLWHA and they mainly received normal treatment support. But the NGOs didn't provide high cost medicine support for them. On the other hand, counseling support was not enough for them which was provided by the non-government support group, and they had a little chance of getting support from government agencies.

\section{Experience of different types of stigma and discrimination:}

Experience of different circumstances at family ground: The family environment was also not free from stigma and discrimination for the respondents. Almost $60 \%$ PLWHA reported that they had experienced block access to spouse and children by the other family members after HIV infection. On the other hand, about $40 \%$ respondents viewed that they were blamed as bad character. 
Table 03: Experience of different situations at family ground $(n=20)$

\begin{tabular}{|l|c|c|}
\hline Experience of different situations at family ground & Frequency & Percentage \\
\hline Blocked access to Spouse and Children & 12 & 60.0 \\
\hline Blame as Bad Character & 8 & 40.0 \\
\hline Severed Relationships, Desertion, Separation & 6 & 30.0 \\
\hline Blamed for Husbands HIV infection & 5 & 25.0 \\
\hline Refused Shelter & 4 & 20.0 \\
\hline Denial of Share of Property or Access to Finance & 4 & 20.0 \\
\hline Denied Access to Treatment and Care & 2 & 10.0 \\
\hline Not Applicable & 6 & 30.0 \\
\hline
\end{tabular}

Note: Increased Percentage due to multiple responses.

About $25 \%$ women viewed that they were blamed for husbands' HIV infection and $20 \%$ PLWHA were refused to get shelter. The case of denial of share of property was happened in $20 \%$ cases and another $10 \%$ were denied access to treatment and care. It was significant that almost 30\% respondents didn't experience the circumstances in their family ground. In this case income, job status and control over family members played a crucial role.

Exclusion of the respondents from social function or practices: More than half of total PLWHA (60\%) were excluded from social functions in the post infection period. Among them 35\% respondents excluded several times from the social functions and on the other hand almost $25 \%$ respondents reported that they were always excluded from the social function. The respondents reported several causes for the exclusion from the social function. This included existence of HIVIAIDS, fear and shame and the selfwithdrawn from the social function.

Experience of physical oppression in the last 12 months and reasons behind the oppres- sion: Physical oppression was experienced by almost $30 \%$ respondents. Among them about $20 \%$ respondents reported that they were oppressed several times in the last 12 months. On the other hand, $10 \%$ respondents viewed that they were oppressed single time. In terms of mode of oppressor, about 6 PLWHA were physically oppressed in the last 12 months. Among them 50\% respondents were oppressed by their husband and about $33.33 \%$ respondents were oppressed by the other family members.

The study revealed that several reasons were responsible for the oppression. A number of female respondents blamed as bad character were oppressed by their parents and family members. In few cases oppression happened for unable to involve in household activities for their illness. A respondent expressed that he was beaten by the local people concerning that he might spread HIVIAIDS. It was also evident about $30 \%$ respondents experienced termination of job after HIV infection, but almost $70 \%$ respondents viewed that they never terminated from the job after infecting HIVIAIDS.

Table 04: Termination of job after HIVIAIDS

\begin{tabular}{|l|c|c|}
\hline Response Category & Frequency & Percentage \\
\hline Several Times & 4 & 20.0 \\
\hline Single Time & 2 & 10.0 \\
\hline Never Happened & 14 & 70.0 \\
\hline Total & 20 & 100.0 \\
\hline
\end{tabular}


Deprived of getting work/job: With regards to being deprived of getting work or job, about $40 \%$ respondents reported that they were deprived of getting work or job after HIV infection. More than half of total respondents viewed that they didn't experience such kind of incidents after HIV infection. The study revealed that most of the PLWHA received support from NGOs and number of PLWHA worked in NGOs in different post like peer educator, counselor, program officer etc. and in this case the NGOs mainly arranged the work or job for them. In another point of view, it was revealed that the number of respondents worked in mill/factory as a labour without disclosing their HIV status.

Disruption of educational activities of the children due to HIVIAIDS: The status of HIVIAIDS also influenced education attainment. About $20 \%$ respondents reported that their children's educational activities were disrupted due to HIVIAIDS for several times. Only $10 \%$ respondents explicated that their children's educational activities were disrupted for single time having HIVIAIDS for them.

Table 05: Disruption of educational activities of the children due to HIVIAIDS

\begin{tabular}{|l|c|c|}
\hline Mode of Disruption & Frequency & Percentage \\
\hline Several Times & 4 & 20.0 \\
\hline Single Time & 2 & 10.0 \\
\hline Never Happened & 8 & 40.0 \\
\hline Not Applicable & 6 & 30.0 \\
\hline
\end{tabular}

Highest $40 \%$ respondents viewed that the incidence of disruption of educational activities were never happened for their children and the issue was not applicable for $30 \%$ respondents because they had no child.

\section{Other types of stigma and discrimination faced by the PLWHA:}

Apart from above issues, the respondents had to face different types of stigma and discrimination in their way of life after being HIV infected. The experience of calling as AIDS in place of their name was a commonly occurred experience in their life. In few cases, denial by the nurses to provide health care services to them also evident. One of the respondent viewed that he was admitted in a hospital and after disclosing his HIV status in the local newspaper by the local journalist, thousands of people came to see him and at a certain stage the agitated people burnt his bed. The study also revealed that it was difficult to arrange marriage for their family members, who were not infected to HIVIAIDS. Number of respondents reported that their children were restricted to mix with the other children of the locality at the initial phase.

\section{Effect of stigma and discrimination from the respondents' family and social life:}

The effects of HIV stigma and discrimination on the respondents were manifested in different ways. Due to HIVIAIDS they had to experience different kinds of circumstances from their family ground to larger society. They were perceived as the shameless character and they were affected to HIVIAIDS due to prohibited activities. Beside these in family ground women were seen as bad character and responsible for husbands' diagnosis. They were excluded from social and religious functions like marriage, kulkahani etc. On the other hand, in several cases they were mentally and physically oppressed in different circumstances by different actors. This unwilling situation created an unthinkable pressure on their psychological health.

Self-assessment of the respondents: It was found that due the effect of stigma and discrimination; felling of ashamed $(70 \%)$ grew 
among the respondents. Apart from this, the issue of feeling suicide $(50 \%)$, blamed them for the HIV infection (40\%), feeling of selfresentment $(35 \%)$ and growing of low stan dard of thinking were reported by the respondents as the consequence of HIV stigma and discrimination (Table 06).

Table 06: Self-assessment of the respondents

\begin{tabular}{|l|c|c|}
\hline Feelings after being HIV Positive & Frequency & Percentage \\
\hline Ashamed & 14 & 70 \\
\hline Feeling of suicide & 10 & 50 \\
\hline Blamed himself/herself & 8 & 40 \\
\hline Self-resentment & 7 & 35 \\
\hline Taken easily & 5 & 25 \\
\hline Growing low standard of thinking & 4 & 20 \\
\hline Condemned by others & 2 & 10 \\
\hline
\end{tabular}

Note: Increased Percentage due to multiple responses.

Decision to exclude from different types of affairs: As the consequence of HIV stigma and discrimination was highly influential on the respondents mind, they decided to exclude them from different state of affairs, which included decided not to take child
(70\%), followed by decided not to participate in social function $(55 \%)$, decided not to intercourse $(25 \%)$, severed relationship from the family $(20 \%)$ and decided not to go to hospital or clinic (15\%).

Table 07: Exclusion of the respondents from different types of affairs

\begin{tabular}{|l|c|c|}
\hline Response category & Frequency & Percentage \\
\hline Decides not to Take Child & 14 & 70 \\
\hline Decides not to Participate in Social function & 11 & 55 \\
\hline Decides not to Intercourse & 5 & 25 \\
\hline Severed relationship from the family & 4 & 20 \\
\hline Decide not to go to hospital or clinic & 4 & 20 \\
\hline Didn't think of above matters & 3 & 15 \\
\hline
\end{tabular}

Note: Increased Percentage due to multiple responses.

\section{Discussion:}

Among the PLWHA, the first case was identified in the year of 1999. Number of respondents reported that they had to test HIVIAIDS due to refer by clinic or hospital. Apart from this, prevalence of STIs and pregnancy related complications inclined the respondents to know the status of HIVIAIDS. Most of the respondents reported that they were informed their HIV status after the checkup while a small portion of them deliberately tested to know their HIV status. In Uganda Heterosexual intercourse $(80 \%)$ and mother to child transmission (22-25\%) identified as the major source of HIV infections.11 While in the present study extra marital sexual affair $(45 \%)$ played a dominant role as the medium of HIV infection. Apart from this, HIV status of partner $(35 \%)$ acted as a source of HIV infection and in $15 \%$ cases the incidence of blood transmission was responsible for HIV infection. 
Fulfilling the need of sexual and reproductive health need for the PLWHA is a challenging and complicated task. ${ }^{12}$ In the present article it was revealed a significant number of respondents had to face difficulties in getting health care services. NGO was identified as the predominant source of getting health care facilities, but they had to wait for a month to get the health care facilities because the health camp was arranged once in a month by the NGO. All the PLWHA had the opportunity to receive ARV from the HIVIAIDS Prevention Project of World Vision Bangladesh. But their concern was that the health project had a predetermined phase (two, three or five years) and after the phase out period they could have to find another source of receiving ARV support. As most of the PLWHA were poor, they didn't get the opportunity to receive high cost of health seeking care and due to lack of confidentiality and negative attitude of the health service providers, they had little opportunity to receive health care services. Most of the respondents received nutrition support from the NGOs but the support was not enough for them, and the support from government agencies was absent, as a result they had to fight for mitigating the required nutritional support.

The STIs treatment and counseling support was not sufficient for them because they had to wait for a month to receive STIs treatment and the counseling support was not qualitative in nature as a result they laid emphasis on the support like regular basis STIs treatment and counseling regarding safe sex and other related issues. Birth control method was available for them which were supplied by NGOs. Most of the respondents were not eager to take child; the major identified reasons were not to increase the number of HIV positive, protect wife from affecting HIVIAIDS, economic problems, not to spoil the future of the child, and so on. In this study it was found that several respondents were eager to take child and they laid emphasis on the support like regular basis treatment support before and after conception, counseling support, proper nutrition support during and after pregnancy. Similarly, "providers at a prevention of mother-to-child transmission (PMTCT) and HIV counseling and testing site in Zambia were found to be missing many opportunities to counsel HIV positive women with family planning messages $\square .{ }^{13}$

HIVIAIDS is gradually being accepted as not merely a medical problem, but a social problem also.14 In USA an opinion poll in late eighties revealed that the infected people were blamed for affecting the situation through their risky behavior.15 The result of the present study showed that PLWHA experienced stigma and discrimination at family, community and social life. Apart from partners and family, their secrecy was reveled without their consent to friends and relatives, local leaders and religious leaders or priest. As a result, their free movement in the locality was distressed at the initial phase and few of them were forced to migrate from the locality. Most of the partners were shocked to know the HIV status of their husband or wife and they accepted them without prejudice while the family members showed discriminatory attitude towards them. The PLWHA showed more sympathetic and cooperative approach to the newly HIV infected persons but the local religious leaders and the local leaders' initial reaction was more discriminatory. In the workplace they experienced heterogeneous attitude by their colleagues and boss like cooperative, sympathetic as well as discriminatory.

More than half of total PLWHA excluded from the social and religious function or practices after the infection of HIVIAIDS. Most of the time they had to experience whispering from community level to the larger social level. The facts of stigma and discrimination, the restriction placed on their free movement, exclusion from social and religious functions, opportunities and participation on the social and 
economic process had direct and often malign consequences for the PLWHAs daily life. The effect of HIV stigma and discrimination was imbedded not only to them but also to their family members. It was quite difficult to arrange marriage for the members of their family; their children were restricted to mix with the other children. Apart from this, the economic hardship to get treatment, restricted condition and the people's misconception and negative attitude towards HIV positive persons influenced to decrease their mental strength. As a result, the phenomena of selfstigma; being ashamed, lower standard of perception towards them, feeling of suicide, and so on embedded upon them.

\section{Conclusion}

Satisfactory sexual and reproductive health care services as well as to reduce the prevailing stigma and discrimination are essential for the people living with HIVIAIDS. The PLWHA had the little access to get satisfactory reproductive health facilities which included quality counseling regarding safe sex, STls treatment, nutrition support, free medical test pregnancy related care, and so on. It was found that the government services were not available for them. On the other hand, due to fear of stigma and discrimination, they were not willing to receive health care support from government agencies. NGO was considered as the only source of getting health care facilities which was not enough for them. The findings suggest that there was a high level of stigmatization and discrimination associated in their social life and due to stigma and discrimination they always lived under the shadow of fear and anxiety. Their secrecy was revealed in some cases without their consent as a result they had to face discriminatory attitude from different peoples at different circumstances. Discrimination in getting job led them to economic hardship and the effect of HIV stigma and discrimination was imbed ded not only to them but also to their family members. It was quite difficult to arrange marriage for the members of their family; their children were restricted to mix with the other children. Therefore, IGA support, continuous nutrition support, ensure quality treatment in the stigma free environment, proper counseling regarding STIs, and widespread awareness campaign regarding HIVIAIDS related issues are highly recommended by the PLWHA. A number of female respondents were eager to take child, but for the conception of HIV infected mother, the support of prevention of mother-to-child transmission facility was highly needed and they laid emphasis on getting this support from the government agencies.

\section{References}

1. Mondal M, Takaku H, Ohkusa Y, Sugawara T, Okabe N. HIVIAIDS Acquisition and Transmission in Bangladesh: Turning to the Concentrated Epidemic. Jpn J Infect Dis. 2009; 62:111-119.

2. Report on the global AIDS epidemic [Internet]. Data.unaids.org. 2008 [cited 26 August 2013]. Available from: http://data.unaids.org/pub/globalreport/20 08/jc1511_gr08_executivesummary_en.p df

3. Gibney L, Saquib N, Metzger J. Behavioral risk factors for STD/HIV transmission in Bangladesh's trucking industry. Social Science \& Medicine [Internet]. 2003;56(7):1411-1424. Available from: http://10.1016/s0277-9536(02)00138-7

4. UNITED NATIONS GENERAL ASSEMBLY SPECIAL SESSION ON HIVIAIDS (UNGASS) [Internet]. Data.unaids.org. 2008. Available from: http://data.unaids.org/pub/report/2008/sai nt_lucia_2008_country_progress_report_ en.pdf 
5. Habib, S. E. Sexual and Reproductive Health Needs of People Living with HIVIAIDS in Bangladesh: An Empirical Account. Social Science Review.2009; 26(1). 158-171.

6. Herek G, Capitanio J. Public reactions to AIDS in the United States: a second decade of stigma. American Journal of Public Health [Internet]. 1993;83(4):574-

577.Available from: http://10.2105/ ajph.83.4.574

7. Warwick I, Bharat S, Castro R, Garcia R, Leshabari M, Singhanetra-renard A et al. Household and community responses to HIV and AIDS in developing countries. Critical Public Health [Internet]. 1998;8(4):311-328. Available from: http://10.1080/09581599808402918

8. Petrak J, Doyle A, Smith A, Skinner C, Hedge B. Factors associated with selfdisclosure of HIV serostatus to significant others. British Journal of Health Psychology [Internet]. 2001;6(1):69-79. Available from: http://htpp://10.1348/ 135910701169061

9. Herek G, Glunt E. An epidemic of stigma: Public reactions to AIDS. American Psychologist [Internet]. 1988;43(11):886-891. Available from: http://10.1037/0003066x.43.11.886

10. Bunting S. Sources of Stigma Associated with Women with HIV. Advances in Nurs ing Science [Internet]. 1996;19(2):64-73. Available from: http://10.1097/00012272199612000-00008

11. Birungi $\mathrm{H}$, Mugisha J, Obare F, Nyombi J. Sexual Behavior and Desires Among Adolescents Perinatally Infected with Human Immunodeficiency Virus in Uganda: Implications for Programming. Journal of Adolescent Health [Internet]. 2009;44(2):184187.Available from: http://10.1016/ j.jadohealth.2008.06.004

12. Baryamutuma R, Baingana F. Sexual, reproductive health needs and rights of young people with perinatally Acquired HIV in Uganda. African Health Sciences. 2011;11(2)(PMC3158520):211-218.

13. Bharat $S$, Mahendra V. Meeting the Sexual and Reproductive Health Needs of People Living with HIV: Challenges for Health Care Providers. Reproductive Health Matters [Internet]. 2007;15(sup29):94. Available from: h t t p://ht t p//10.1016/s 0968 8080(07)29030-5

14. Mawar, N., Sahay, S., Pandit, A. and Mahajan, U., 2005. The third phase of HIV pandemic: Social consequences of HIVIAIDS stigma \& discrimination \& future needs. Indian J Med, Res 122, pp 471484.

15. Gallup G. Survey results indicate difficulties gays face in a heterosexual society. The Gallup Opinion Index 1977; 147: 17 